Issues in Information Systems

Volume 18, Issue 2, pp. 95-102, 2017

\title{
LEVERAGING INFORMATION TECHNOLOGY TO CREATE SUSTAINABLE SUPPLY CHAINS
}

\author{
Mysore Ramaswamy, Southern University, Baton Rouge, LA, mysore@acm.org
}

\begin{abstract}
In today's global economy, supply chain sustainability has become a critical issue for many companies. Recent innovations in information technology (IT) have positively impacted all aspects of business including the field of supply chain management (SCM). With the emergence of web services, the convergence of telecom and computing is finally reaching maturity in a unified platform for doing business in the $21^{\text {st }}$ century. The role of IT in SCM has been well studied. However there is still a dearth in the current literature that analyzes how this digital technology can help in developing sustainable supply chains. This paper seeks to fill this gap by analyzing how IT can help sustainability of all links of the supply chain and examining specific functions suitable for application of digital technology. It is essential that sustainable business processes are identified based on their cost, complexity, and criticality and then reengineered and automated based on analyzing the domain specific data.
\end{abstract}

Keywords: Information Technology, Supply Chain, Sustainability, Green Business

\section{INTRODUCTION}

Supply chains must respond to environmental pressures from four sources. Resource availability and regulatory pressures place physical, legal, and economic constraints on supply chain management, while consumer demands and the ethical responsibilities of corporations define desirable behavior in the and within those constraints (Paquette, 2006). As a result of this, supply chain sustainability has become a critical issue for many companies. Recent innovations in information technology (IT) have positively impacted all aspects of business including the field of supply chain management (SCM). With the emergence of web services, the convergence of telecom and computing is finally reaching maturity in a unified platform for doing business in the $21^{\text {st }}$ century. The widespread availability of highly flexible, functional, and inexpensive information and communication technologies provides us with opportunities for a radical redesign of supply chains (Gunasekaran, 2004). Redesign of supply chain should include a rethinking with sustainability in the background.

Information is an important asset that gives enterprises a competitive advantage in the new economy. Information access plays a critical role in the informed decision making process, making it easy for businesses to make good competitive decisions (Bansal, 2005; Jain, 2009)). The ability of organizations to survive in an increasingly competitive global environment is largely predicated upon their capacity to leverage information as a resource. In today's fierce competitive environment, companies need to be highly responsive and adaptive to demands of customers, actions of competitors, and changes in economic conditions (Bharadwaj, 2007; Simchi-Levi, 200). Data analytics can be as useful to businesses by identifying those business processes that are capable of exploiting the new innovations in that area.

A business case can be made for companies to be committed to sustainability (Keating, 2008). Corporate and social responsibility (CSR) has emerged as a key area of concern for industry since it came to prominence in the 1970s. CSR is an organizational philosophy that directs firms to consider and minimize the negative social impact of their profit making activities. In recent years, firms have embraced the importance of working collaboratively with their supply chain partners to enhance their CSR performance.

This paper is organized as follows. First we briefly describe the current scenario pertaining to supply chain management and sustainability. The role of information technology in sustainable supply chain management is 
discussed subsequently. Business process reengineering relevant to supply chains using information technology is discussed next. Concluding remarks form the last section.

\section{SUPPLY CHAIN MANAGEMENT AND SUSTAINABILITY}

The concept of sustainability is not a new idea. In 1987, the Brundtland Commission (World Commission on Environment and Development) stated that sustainability is development that meets the needs of the present without compromising the ability of future generations to meet their needs. Business sustainability can be defined as the ability to conduct business with a long term goal of maintaining the prosperity of the economy, environment and society. This is well described in the triple bottom line (TBL) perspective of sustainability which considers organizational sustainability to include the following three components:

- Environmental Performance (Planet),

- Economic Performance (Profitability), and

- Social Performance (People).

By considering all stakeholders in addition to profits, more sustainable outcomes can be chosen while considering many alternatives. Nearly $70 \%$ of the top 250 global companies on the Fortune 500 have adopted TBL reporting (Dao, 2011). The Dow Jones Sustainability Indices (DJSI) launched in 1999, are a family of indices evaluating the sustainability performance of the largest 2,500 companies listed on the Dow Jones Global Total Stock Market Index. Companies vie for a better Dow Jones Sustainability Index.

In a typical manufacturing enterprise, the value chain model consists of the following sequence of activities: inbound logistics, operations, outbound logistics, marketing \& sales, and service. The objective is to offer the customer a level of value that exceeds the cost of activities (Chopra, 2007). In addition to the above primary value chain activities, we also need to consider the following supporting activities: firm infrastructure, human resource management, technology development, and procurement. Supply chain management (SCM) can be defined as the combination of art and science of improving the way an enterprise finds the raw components it needs to make a product and delivers it to customers. Viewed from this perspective, SCM is an important part of the overall value chain model. This approach is useful in analyzing the impact of Information and Communications Technologies (ICT) on the manufacturing environment. Sustainability affects all links of the supply chain.

Typically, a supply chain includes all entities and processes involved in fulfilling a customer order. More than one decision maker is involved in managing resources, information, and processes that span several organizations. In a nutshell, supply chain consists of the following stages:

- Sourcing,

- Transformation,

- Delivery,

- Product Use, and Recycle.

Sourcing refers to procurement of raw materials, parts, and subassemblies required for the production of the final product. A critical part of sustainable supply chain is to have procurement that support environmentally friendly practices. This will be effective when the major entity in the supply chain forces its upstream suppliers to adopt and adapt technology and practices that result in sustainable material sources.

Transformation refers to the conversion of inputs to outputs. Using electricity produced from green alternatives instead of fossil fuels, using recycled paper and plastics where possible and using non-toxic chemicals in their processes are some of the ways to ensure sustainability. The delivery stage includes many operational processes. The choice of facility location such as offshore vs. onshore, close to the customer vs. close to the raw material source can have a significant impact on the green house gas (GHG) emissions. The choice of mode of transportation is another critical factor. Rail and waterways have lower emissions for ton of goods shipped but they are slower than trucks and airplanes which have higher costs and emissions. Inventory management is another area that can impact sustainability. Single period and multi-period inventory models take into consideration stock out and backorder costs but not sustainability criteria. 
Consumers have a critical role to play in making supply chain sustainable. Considering products such as cars and computers, a major proportion of emissions comes from consumer's use of products. A key objective of any business should be to make goods that are more energy efficient. A key component of Closed-loop supply chains is the concept of reuse, recycle and return. The objective is to ensure that the product is eventually disassembled and components reused, re-manufactured or recycled into a source of raw materials. Appendix I indicates the role of information technology in the different supply chain functions.

Elkington (2004) argues that due to the advance of information technology (IT) companies can no longer keep their practices secret from stakeholders. They have to report on their sustainability practices to inform them and to serve as a benchmark against competitors. Hassini (2012) lists the following factors as drivers for the adoption of sustainable supply chain practice:

- Market Forces,

- Policy and Regulations,

- Science and Technology,

- Product Development,

- Process Capability,

- Sourcing and Operations,

- Transport and Logistics,

- Marketing and PR, and

- Social Issues.

Market forces factors include consumers, retailers, original equipment manufacturers who may demand products considered environmentally friendly from their suppliers. Financial stakeholders such as mutual funds and pension funds require that the company follow sustainable practices. It is likely that in the future, access to capital markets may be restricted only to businesses that are deemed to be environmentally friendly. Competition in the marketplace may require a company a company to offer product considered as socially responsible, green, or sustainable. Governments either through legislation or via a regulator requiring that companies adhere to certain environmental standards is an example of hoe policy and regulations can influence companies to consider sustainability. In case of environmental disasters, governments can retroactively introduce legislation or regulation to curtail some business practices. Klassen and Vachon (2003) found that adoption of ISO 4001 is significantly related to the efforts of companies to invest more in environmental management practices.

The science and technology factor stems from the need to use research and development division to find materials and processes that are not toxic, use less energy or suitable substitutes without compromising use. The product development factor involves using more recycled content, using biodegradable materials or alternative sources of fuels and materials. It also calls for using reverse logistics and design for disassembly. The process capability factor calls for greening the process. This involves using energy efficient machines, fuel efficient transportation, etc. The process of producing the product will have to be environmentally sustainable. In case of returns after the useful life of the product, the supply chain would also have to ensure that the process is capable of absorbing returns and use them back in the production process,

The sourcing and operations factors focuses on sourcing of recycled or renewable raw materials, parts or subcomponents and use processes that are more environmentally friendly. Companies like Subaru and Toyota operate zero-waste facilities as a means of reducing costs and helping the environment. They secure zero waste by making sure that no byproduct of their operations ends up in a landfill. The transport and logistics factors direct companies require the use of reverse logistics and closed loop supply chains and reuse, recycle, and return programs.

The marketing and public relations factors pertain to the efforts of companies to create a value proposition to customers. Companies have to create awareness of the practices that makes the product more environmentally friendly and sustainable. Carbonfund and Bullfrogpower are organizations that provide carbon offsetting and greenhouse gas reduction options to businesses, and organizations. Companies can use certifications from such entities to inform customers that their products are environmentally friendly. The social issues factor focuses more on the existing behavior and practices of companies in relation to the treatment of their labor force, sourcing practices and 
environmental impact on their communities (Wang and Lin, 2007). Sustainable operations are more concerned with translating laudable aspirations into economically sustainable business practices.

\section{ROLE OF INFORMATION TECHNOLOGY IN SUSTAINABILITY}

Enterprise resource planning (ERP) and supplier management systems alone cannot provide capabilities to achieve transparency, enhance their supplier base and processes for managing suppliers, and improve the ability to assess and address issues at the supplier, factory, and subcontractor levels. Companies are looking for ways to leverage and enhance technology solutions to support visibility, collaboration, and communication. The proliferation of mobile technology and cloud software systems has created a boom in supply chain technology solutions (UN Global Compact, 2016). Information technology enables supply chain and procurement executives to better understand their supply chain characteristics, get a better handle on supplier performance, and more successfully manage sustainability risks.

Domain specific solutions vary significantly in their focus, capabilities, and sophistication but are moving from data collection to verifications, communication and visualization of supplier inputs. The technology offerings are increasingly focusing on efficiency, accountability, resiliency, and providing a single source of supply chain information. Companies from the agricultural and food and beverages sector, for example, use information technology in their supply chain to improve business efficiency by tracking natural resources (e.g., water), commodities (e.g., grains), and chemicals (e.g., fertilizers).

Numerous solutions have been developed focusing on accountability, which is a huge component of sustainable supply chain. Companies like "EcoVadis" build supplier databases that rely on direct interactions with supplier inputs, leading to increased supplier engagement, and incorporating external sources such as government platforms to collect and analyze data and derive real-time insights to guide better business decisions. The following is a list of different means through which information technology can be used to create sustainable supply chains:

- Interface with the customer to provide real-time information relating to the supply chain,

- Integration with supplier management systems, and enterprise resource planning systems,

- Supply chain partners connected via one platform,

- Comprehensive analysis tools for categorization and selection of vendors,

- Learning and survey capabilities to foster education for suppliers,

- Dashboard that displays supplier profile, factory risks and key performance indicators,

- Utilizing emerging, real-time data sources to monitor supplier performance,

- Leveraging cloud-based modules to execute compliance/audit plans, including logistics, reporting and traceability.

\section{SUSTAINABILE PROCESS REENGINEERING}

Redesign, retooling, and re-orchestrating form the key components of Business Process Reengineering (BPR) that are essential for an organization to focus on the outcome that it needs to achieve. These stages have key steps as indicated in Appendix II. The entire technological, human, and organizational dimensions may be changed in BPR. Information technology plays a major role in business process reengineering as it provides office automation, it allows the business to be conducted in different locations, provides flexibility in manufacturing, permits quicker delivery to customers and supports rapid and paperless transactions (Bogdanoiu, 2014; Wu, 2005).

The BPR technique implements organizational change based on rapid change, employee empowerment, and training and support by information technology. In order to implement BPR to an enterprise, the following key actions need to take place:

- Selection of the strategic processes for redesign,

- Simplify new processes - minimize steps - optimize efficiency - modeling,

- Organize a team of employees for each process,

- Organize the workflow - document transfer and control,

- Assign responsibilities and roles for each process,

- Automate processes using information technology, 


\section{Issues in Information Systems}

Volume 18, Issue 2, pp. 95-102, 2017

- Train the process team to efficiently operate the new process,

- Introduce the redesigned process into the new organizational structure.

Although technology can create new or modified business practices at a rapid rate, successful adoption of new best practices must stand up to market forces. Technology and the marketplace are continually reshaping business activities and as a consequence, business strategies. An organization must continually work towards an alignment that fits into the organization's sustainability strategy and IT strategy. This alignment should improve the likelihood that new initiatives are explicitly linked to areas that are critical to successful business performance, provide a source of competitive advantage. The role of IT should be that of a strategic enabler for competitive success, rather than just an operational supporter. As indicated in Appendix I, information technology tools are well suited for develop strategies to create sustainable supply chain functions.

Dao (2011) proposes an integrated sustainability framework as shown in Appendix III. Short term internal strategy emphasizes preventing pollution by optimizing internal operations to reduce cost and have a positive impact on the environment. Strategy also involves creating an organizational culture aimed towards sustainability and improving employee management practices within firms. Payoffs envisaged for activities in this quadrant are reduced costs, increased profitability, and reduced risk. Short term external strategy focuses on improving the extended supply chain to reduce pollution through material and process choices and closed loop supply chain. Strategy also involves extending organizational culture aimed towards addressing sustainability issues affecting both internal and external stakeholders. Payoffs expected for this strategy include reputation, legitimacy, reduced environmental impacts, and increased competitive advantage.

Long term internal strategy involves developing capabilities that enable radical clean technologies and processes that help solve social and environmental issues. Expected payoff for this strategy includes innovation and strategic positioning. Long term external strategy consists of including core sustainability capabilities in all products, processes, and supply chains. This strategy will give an impetus to open new, previously ignored dialogues with stakeholders to solve social issues and locate growth opportunities, thus creating a sustainability vision. Expected payoff would be a positive growth trajectory. As Paquette (2006) points out, a company that is reactive, flexible, and efficient in execution may operate extremely well at environmental pressure, while a company that is proactive, innovative, and differentiated from competition may best place themselves beyond pressure.

\section{CONCLUSION}

Enterprises of all sizes that are parts of supply chain can benefit from using techniques made available by information technology in their efforts to create a sustainable supply chain. Business process engineering and data analytics have been used successfully in the corporate world. However, optimal use of these techniques focused towards sustainability requires domain specific analysis (Watson, 2010). The basic building blocks of IT implementation consist of digitized versions of interactions among various business processes. In this paper, we have presented a framework that can identify and categorize the different types of business processes/transactions geared towards sustainability.

Various processes that can be created through information technology to help create sustainable supply chains have been analyzed. Restructuring these processes and then automating them in a systematic affords a practical approach to leverage information technology. Monitoring the critical success factors will help in evaluating the success of these measures. Future work in this area focuses on developing a comprehensive framework that will enable entrepreneurs and researchers to point out the potential priority areas that need to be automated first and also yield a realistic estimate of resources needed to achieve such transformation. In addition, such an approach will also help in giving a better insight into process restructuring with sustainability as the main focus. 


\section{REFERENCES}

Bansal, P. (2005). Evolving sustainability: a longitudinal study of corporate sustainability development. Strategic Management Journal, 26, 197-218.

Bharadwaj, S., Bharadwaj, A., \& Bendoly, E. (2007). The performance effects of complementarities between information systems, marketing, manufacturing, and supply chain processes. Information Systems Research, 18(4), 437-453.

Bogdanoiu, C. (2014). Business Process Reengineering Method. Retrieved March, 14, 2017, from http://www.cesmaa.eu/ awards/ Best Student Paper_BogdanoiuCristiana.pdf

Carter, C. R., \& Rogers, D. S. (2008). A framework of sustainable supply chain management: moving toward new theory. International Journal of Physical Distribution \& Logistics Management, 38(5), 360-387.

Castka, P., \& Balzarova, M. (2008). ISO 26000 and supply chains - On the diffusion of the social responsibility standard. International Journal of Production Economics, 111(2), 274-286.

Chen, A., Boudreau, M., \& Watson, R. (2008). Information systems and ecological sustainability. Journal of Systems and Information Technology, 10(3), 186- 201.

Chopra, S., \& Meindl, P. (2007). Supply Chain Management: Strategy, Planning, and Operation, 3rd ed. Prentice Hall, Upper Saddle River.

Christopher, M., Peck, H. (2004). Building the Resilient Supply Chain, International Journal of Logistics Management, 15(2), 1-13.

Dao, Viet, S., Langella, I., Carbo, J. (2011). From Green to Sustainability: Information Technology and an Integrated Sustainability Framework. Journal of Strategic Information Systems, 20, 63-69.

Elkington, J. (2004). Enter the triple bottom line. In: Henriques, A., Richardson, J. (Eds.), The Triple Bottom Line: Does It All Add up? Earthscan, London, 1- 16.

Gunasekaran, A., Ngai, E. W. T. (2004). Information Systems in Supply Chain Integration and Management. European Journal of Operational Research, 159, 269-295.

Hassini, Elkafi, J., Surti, C., Searcy, C. (2012). A Literature Review and a Case Study of Sustainable Supply Chains with a Focus on Mterics. International Journal of Production Economics, 140, 69-82.

Hervani, A. A., Helms, M. M., Sarkis, J. (2005). Performance measurement for green supply chain management. Benchmarking: An International Journal, 12(4), 330-353.

Jain, V., Wadhwa, S., Deshmukh, S. G. (2009). Revisiting information systems to support a dynamic supply chain: issues and prospective. Production Planning \& Control, 20, 17-29.

Keating, B., Quazi, A., Kriz, A., Coltman, T. (2008). In Pursuit of a Sustainable Supply Chain. Supply Chain Management, 13(3), 173-179.

Klassen, R. D., Vachon, S. (2003). Collaboration and evaluation in the supply chain: the impact on plant-level environmental investment. Production and Operations Management, 12(3), 336-352.

Kleindorfer, P. R., Singhal, K., Van Wassenhove, L. N. (2005). Sustainable operations management. Production and Operations Management, 14, 482-492. 
Lee, H. L. (2000). Creating value through supply chain integration. Supply Chain Management Review, 4(5), 30-36.

Linton, J. D., Klassen, R., Jayaraman, V. (2007). Sustainable Supply Chains: An Introduction. Journal of Operations Management, 25, 1075-1082.

Melville, N. (2010). Information systems innovation for environmental sustainability. MIS Quarterly, 34(1), 1-21.

Paquette, J. (2006). The Supply Chain Response to Environmental Pressures. Retrieved April, 7, 2017, from http://dspace.mit.edu/handle/1721.1/34530

Porter, M., \& Kramer, M. (2006). Strategy and society: the link between competitive advantage and corporate social responsibility. Harvard Business Review, 84(12), 78-92.

Shah, N. (2005). Process Industry Supply Chains: Advances and Challenges. Computers and Chemical Engineering, 29, 1225-1235.

Simchi-Levi, D., Kaminsky, P., \& Simchi-Levi, E. (2000). Designing and Managing the Supply Chain: Concepts, Strategies, and Case Studies. Irwin/McGraw-Hill, New York.

Stonebraker, P. W., Goldhar, J., Nassos, G. (2009). Weak links in the supply chain: measuring fragility and sustainability. Journal of Manufacturing Technology Management, 20, 161-177.

UN Global Compact (2016). The State of Sustainable Supply Chains. Retrieved February, 26, 2017, from http://www.ey.com/Publication/ vwLUAssets/ EY-the-state-of-sustainable-supply-chains

Wang, L., Lin, L. (2007). A methodological framework for the triple bottom line accounting and management of industry enterprises. International Journal of Production Research, 45(5), 1063-1088.

Watson, R., Boudreau, M., Chen, A. (2010). Information systems and environmentally sustainable development: energy informatics and new directions for the IS community. MIS Quarterly, 34(1), 23-38.

Wu, F., Mahajan, V., Balasubramanian, S. (2005). An Analysis of E-Business Adoption and Its Impact on Business Performance. Journal of the Academy of Marketing Science, 31(4), 425-447. 


\section{APPENDIX}

Appendix I. Role of IT in SCM

\begin{tabular}{|l|l|}
\hline Supply Chain Function & Role of Information Technology \\
\hline Sourcing & $\bullet$ E-Procurement \\
\hline Transformation & $\begin{array}{l}\bullet \text { Computer Aided Design } \\
\bullet \text { Computer Aided Manufacturing } \\
\bullet \text { Enterprise Resource Planning }\end{array}$ \\
\hline Delivery & $\bullet$ Logistics Information Systems \\
\hline $\begin{array}{l}\text { Product Use and } \\
\text { Recycle }\end{array}$ & $\bullet$ Online Assistance \\
\hline
\end{tabular}

Appendix II. The 3 Rs of Reengineering

\begin{tabular}{|l|l|l|}
\hline REDESIGN & RETOOL & REORCHESTRATE \\
\hline$\bullet$ Simplify & $\bullet$ Networks & $\bullet$ Processes \\
$\bullet$ Standardize & $\bullet$ Intranets & $\bullet$ Information \\
$\bullet$ Empower & $\bullet$ Extranets & Technology \\
$\bullet$ Measure & $\bullet$ Workflow & $\bullet$ Human Resources \\
\hline
\end{tabular}

Appendix III. Integrated Sustainability Framework [Adapted from (Dao. 2011)

\begin{tabular}{|c|c|c|}
\hline & Internal & External \\
\hline Today & $\begin{array}{l}\text { Strategy } \\
\text { Prevent Pollution via Optimizing } \\
\text { Operation to reduce cost and impacts on } \\
\text { the environment } \\
\text { - Create organizational culture aimed } \\
\text { towards sustainability, Improve } \\
\text { employee management practices within } \\
\text { firms } \\
\text { Payoff } \\
\text { - Reduced costs, increased profitability, } \\
\text { reduced risk }\end{array}$ & $\begin{array}{l}\text { Strategy } \\
\text { - Improve extended supply chain to reduce } \\
\text { pollution through material and process } \\
\text { choices and closed-loop supply chain } \\
\text { - Extend organizational culture aimed } \\
\text { towards addressing sustainability issues } \\
\text { affecting both internal and external } \\
\text { stakeholders } \\
\text { Payoff } \\
\text { - Reputation and legitimacy, Reduced } \\
\text { environmental impacts, Increased } \\
\text { competitive advantage }\end{array}$ \\
\hline Tomorrow & $\begin{array}{l}\text { Strategy } \\
\text { - Develop capabilities that enable } \\
\text { radical clean technologies and processes } \\
\text { that help solve social and environmental } \\
\text { issues } \\
\text { Payoff } \\
\text { - Innovation, Strategic Positioning }\end{array}$ & $\begin{array}{l}\text { Strategy } \\
\text { - Include core sustainability capabilities in } \\
\text { all products, processes, and supply chains } \\
\text { - Sustainability Vision: Open new, } \\
\text { previously ignored dialogues with } \\
\text { stakeholders to solve social issues and } \\
\text { locate growth opportunities } \\
\text { Payoff } \\
\text { - Growth trajectory }\end{array}$ \\
\hline
\end{tabular}

